\section{Europe's new space launcher stays on the launch pad}

Ariane, Europe's 200-tonne 3-stage launcher designed to put 1-tonne payloads into geostationary orbit, stayed resolutely on its launch-pad last Saturday during the first attempt to put the vehicle into space. Journalists, watching closed-circuit television screens at the European Space Agency's headquarters in Paris gripped their notebooks excitedly, and radio reporters cleared lines to their news bureaus, as the seconds ticked away to zero. With a few seconds to go, the two "cryogenic arms" which had fuelled the rocket in the previous hours and minutes swung away; there was a cloud of vapur was it taking off?

No. Ignition was due at zero seconds. Lift-off at $+3 \mathrm{~s}$. Four seconds, five seconds after zero - was it going to explode, like the first V2s, or like the previous European rocket, Europa, which blew up shortly after take-off? "Mondieu"' said the radio man next to me into his telephone. I peered more closely at the screen, thinking he'd spotted something. But then the vapour drifted away, Ariane looked just as before. Anticlimax. ESA officials, long-faced, made for the bar, where the whisky bottles were quickly emptied.

Then the details began to come through. One of the four main engines of the first stage had failed to reach the planned pressure of 9 atmospheres at its combustion chamber - it had reached only 5 atmos - and the computer automatically controlling the last five minutes of launch wisely decided to close the fuel valves. According to some accounts this decision had been made within 0.1 s of ignition, accounting for the puff of vapour.

When the disappointment had abated a little, Brian Stockwell, deputy head of the Ariane programme in ESA, said that he'd give 50-50 that it was an instrument rather than an engine failure. "The engines have been fully qualified"' he said. Engines early in the development phase had failed to reach design pressure, or had done so more slowly than others, but the problems had been ironed out. The particular engines on this vehicle had never been fired, but they came from a series which was fully proven.

By Monday, detailed records made at the Kourou, French Guiana launch site of the operation of the engines were supporting Stockwell's opinion. An ESA statement said that a malfunction of two pressure sensors on one of the engines "is very clearly shown by the recordings and is attributable to a local overpressure occurring in their feed line shortly after engine ignition, thus putting them out of order. Appropriate steps to avoid a recurrence of such an incident are under study",

Re-launch is planned for next week, the statement says, the time being taken up by re-equipping the vehicle with seals that have been broken and reversing other 'oneway' changes that are made in the last few minutes of the launch sequence. Ariane must also be checked to see if its brief ignition caused any damage.

Officials are therefore hopeful that Ariane will fly with the first and second

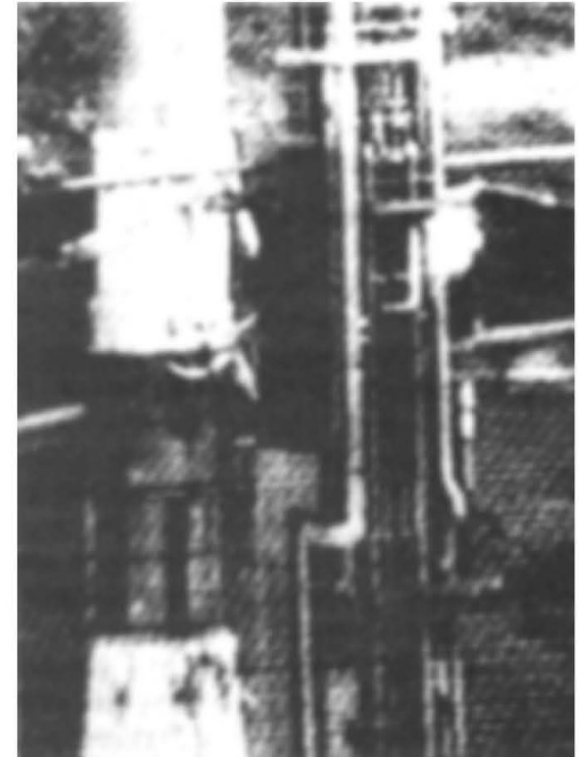

Ariane just before zero seconds

stages functioning normally. But the third stage, using liquid hydrogen and oxygen, is more doubtful.

While versions of the first and second stages have both been fired successfully in ground tests, the third stage remains to be 'qualified'. In its most successful ground firing, the engines burned only for $90 \mathrm{~s}$, instead of the designed 150s. Full qualification is not expected until February, before the launch of a second Ariane; so ESA officials are looking on this first launch as a development flight rather than a test launch. And if of the first four launches planned for the next year, two Arianes successfully put their test packages into orbit, ESA will consider they have a success.

Robert Walgate

\title{
UK genetic engineering regulations relax gradually
}

THE outcome of the UK Genetic Manipulation Advisory Group's programme to assess the risk from recombinant DNA experiments has been a gradual lowering of the categories of physical containment under which many experiments are now being done, according to Sir William Henderson, chairman of the group. The programme, suggested by $\mathrm{Dr}$ Sydney Brenner of the MRC Laboratory of Molecular Biology, Cambridge at the end of 1978 (Nature 276, 104; 1978), identified the type of host vector system as a crucial factor in designing safe experiments.

The development of safe host vector systems over the past year has meant that about $90 \%$ of recombinant DNA experiments can now be done under the first two categories of physical containment laid down by the Williams guidelines. Experiments which still come under categories III and IV are mainly those involving the expression of toxins or hormones.

GMAG had been slightly embarrassed, said Sir William when introducing the group's second annual report last week, when the National Institutes of Health in the US proposed 'relaxing' its guidelines about a year ago. At that time, genetic engineering experiments in the UK still came under the more stringent guidelines laid out in the Williams report. Now, however, it was extremely difficult to detect the practical difference between the two systems, said Sir William. The percentage of experiments coming under categories I and II had increased steadily over the past few months from $66 \%$ in July to $90 \%$ in December.

The procedure of notification of experiments has also changed over the past year. Notification to GMAG and the Health and Safety Executive is now compulsory. Synopses of experiments together with details of the DNA and host vector systems to be used have to be submitted to both bodies and local genetic manipulation safety committees have to recommend the category under which they think the work should be done. Work under categories I and II can begin as soon as GMAG and HSE are notified.

Initial concern that local committees would be incapable of judging categories has not been substantiated. In only one case, said Sir William, did GMAG have to increase the category of containment and on a few occasions it had even recommended lower containment with the used of improved host vector systems.

Despite the success of the past year, however, the members of GMAG still see a need for careful monitoring of recombinant DNA experiments. Most experiments are now done with disabled host vector systems which would not have been developed if GMAG had not existed, said Professor Bob Williamson of St Mary's Hospital Medical School, London and a member of the group. If GMAG ceased to exist now most of the awareness amongst scientists of the need for safety in experiments with recombinant DNA, which it had helped to create, would vanish.

The major problems which GMAG will be tackling over the coming year include industrial scale-up - one case has already arisen - and genetic manipulation in crops.

Judy Redfearn 